\title{
Influence of Certain Pulsed Electric Field Conditions on the Growth of Lactobacillus acidophilus LA-K
}

\section{Cueva $\mathrm{O}^{1}$ and Aryana $\mathrm{KJ}^{1,2 *}$}

${ }^{1}$ School of Animal Sciences, Louisiana State University Agricultural Center, Baton Rouge, LA 70803, USA

${ }^{2}$ Department of Food Science, Louisiana State University Agricultural Center, Baton Rouge, LA 70803, USA

\begin{abstract}
Pulsed Electric Field (PEF) processing involves the application of pulses of electricity, for less than one second to fluid products placed between two electrodes. Lactobacillus acidophilus is an important probiotic bacterium used for the production of fermented dairy foods. The objective was to study the influence of electric pulse period, electric field strength, and electric pulse width on the growth of Lactobacillus acidophilus LA-K. Lactobacillus acidophilus LA-K, suspended in sterile peptone water was treated using an OSU-4 PEF processor. The treatments were pulse periods of $10,000,20,000$ and $30,000 \mu$ s electric field strength of 5,15 and $25 \mathrm{kV} / \mathrm{cm}$, and pulse widths of 3,6 and $9 \mu \mathrm{s}$. Growth was determined hourly for 16 hours of anaerobic incubation at $37^{\circ} \mathrm{C}$. Pulse period had a significant $(p=0.0017)$ influence on the growth. There were no significant differences among the control, $30,000 \mu$ s and 20,000 $\mu s$. The growth of Lactobacillus acidophilus subjected to the pulse period of $10,000 \mu$ s was significantly lower than the growth of the control, and the growth when subjected to $30,000 \mu \mathrm{s}$. Electric field strength had a significant $(p<0.0001)$ influence on the growth. Growth subjected to 15 and $25 \mathrm{kV} / \mathrm{cm}$ was significantly lower than the control and $5 \mathrm{kV} / \mathrm{cm}$. There were no significant differences between the control and $5 \mathrm{kV} / \mathrm{cm}$. There were no significant differences between the growth, when Lactobacillus acidophilus was subjected to 15 and $25 \mathrm{kV} / \mathrm{cm}$. Bipolar pulse width effect had a significant $(p<0.0001)$ influence on the growth. Growth of the control was significantly higher than the growth of Lactobacillus acidophilus subjected at any of the bipolar pulse widths studied. There were no significant differences in growth among the three different bipolar pulse widths. Electric field strength significantly influenced growth of Lactobacillus acidophilus LA-K. Bipolar pulse width and pulse period slowed log stage growth of Lactobacillus acidophilus LA-K. Slower growth of adjunct bacteria can sometimes be good in the manufacture of cultured dairy foods, as it results in controlled release of bacterial enzymes for improved flavor and texture development.
\end{abstract}

Keywords: Non thermal; Probiotic; Acidophilus; PEF

\section{Introduction}

Temperature has been used to kill microorganisms (pasteurization), grow microorganisms (incubation) and preserve microorganisms (freezing). Temperature is widely used in food processing to kill the pathogens, to result in a safe product for consumption. High temperatures kill pathogens in food, but have several disadvantages on the food product, including loss of heat sensitive components. Example: loss of heat sensitive vitamins, denaturation of some proteins and induction of cooked flavors, which is a sensory defect. To avoid these disadvantages in a food product and yet kill the pathogens, there is increased interest in non thermal processing. Pulsed Electric Field (PEF) is one of the non thermal hurdle technologies gaining interest.

Pulsed electric field involves passage of pulses of electricity to fluid food that flow between two electrodes. The destruction of pathogens is achieved by irreversible electroporation. Destruction of pathogens in liquid media using PEF has been reported earlier.

Pothakamury et al. [1] obtained a 5 log reductions in Escherichia coli counts by applying 60 pulses, $16 \mathrm{kV} / \mathrm{cm}$ and $300 \mu$ s. These results were compared with those obtained by using heat $\left(82.2^{\circ} \mathrm{C}, 171 \mathrm{~s}\right)$, which produced $5 \log$ reductions, but caused degradation of organoleptic and nutritive characteristics. Qin et al. [2] achieved more than a 6 log cycle reduction in E. coli, using electric field intensity of $36 \mathrm{kV} / \mathrm{cm}$ and 50 pulses PEF treatment. The temperature of the chamber in this study was maintained below $40^{\circ} \mathrm{C}$ during the PEF treatment, which is lower than the temperature of commercial pasteurization $\left(70-90^{\circ} \mathrm{C}\right)$ for milk. Grahl and Markl [3] reported the influence of pulse number in microbial inactivation of $E$. coli. They were able to reduce the populations of $E$. coli in UHT milk by 1, 2 and $3 \log$ cycles when 5,10 , and 15 pulses at 22 $\mathrm{kV} / \mathrm{cm}$ were applied. The killing effect of PEF on Escherichia coli ATCC 8739 suspended in an orange juice and milk beverage was studied by Rivas et al. [4]. Bipolar square pulse widths with a pulse width of $2.5 \mu \mathrm{s}$, electric field strengths from 15 to $40 \mathrm{kV} / \mathrm{cm}$, and treatment times from 0 to $700 \mu$ s were applied in this study. They found a maximum of 3.83 $\log$ reductions with $15 \mathrm{kV} / \mathrm{cm}$ and $700 \mu$ s, and no significant differences at the electric field strength range from $25-40 \mathrm{kV} / \mathrm{cm}$.

Effect of PEF on many other pathogens has also been studied. Fernandez-Molina et al. [5] reported 2.6 and 2.7 log reductions for different microorganisms such as Listeria innocua in raw skim milk $(0.2 \%$ milk fat) and Pseudomonas fluorescens with $2 \mu \mathrm{s}, 100$ pulses and $50 \mathrm{kV} / \mathrm{cm}$ at room temperature. They achieved $3.5 \mathrm{log}$ reductions using $29 \mathrm{kV} / \mathrm{cm}, 4 \mu \mathrm{s}$, and $71.3 \mu$ s of total treatment time. Sobrino-López et al. [6] reached a $4.5 \mathrm{log}$ reduction in Staphylococcus aureus by applying 150 bipolar pulses of $8 \mu \mathrm{s}$, each at $35 \mathrm{kV} / \mathrm{cm}$. They found bipolar pulses to be more effective than monopolar pulses.

*Corresponding author: Kayanush Aryana, Department of Food Science Louisiana State University Agricultural Center, Baton Rouge, LA 70803, USA, E-mail: KAryana@agcenter.Isu.edu

Received August 08, 2012; Accepted November 16, 2012; Published Novembe 19,2012

Citation: Cueva O, Aryana KJ (2012) Influence of Certain Pulsed Electric Field Conditions on the Growth of Lactobacillus acidophilus LA-K. J Microb Biochem Technol 4: 137-140. doi:10.4172/1948-5948.1000084

Copyright: ( 2012 Cueva O, et al. This is an open-access article distributed under the terms of the Creative Commons Attribution License, which permits unrestricted use, distribution, and reproduction in any medium, provided the original author and source are credited 
Although there is extensive literature on use of PEF conditions to kill pathogens, there is scanty literature on PEF conditions to modulate growth of desirable bacteria. Just as high temperatures are used to kill pathogens and mild temperatures are used to grow culture bacteria, it is not known if pulsed electric field can have a similar effect. The hypothesis was whether certain "mild" pulse electric field conditions can modulate the growth of the probiotic bacterium Lactobacillus acidophilus LA-K, without killing it. Cultured food such as yogurt and cheese contain bacterial cultures of at least a million cfu's/g. These modulated growths of culture bacteria are needed in cultured food products in various applications, such as enhanced textures and flavors during cheese ripening, and milder sourness in yogurt with enhanced flavors. The objective was to study the influence of electric pulse period, electric field strength and electric pulse width on the growth of Lactobacillus acidophilus LA-K.

\section{Materials and Methods}

\section{Sample preparation and treatment}

Samples for the growth were prepared by inoculating $1 \%(\mathrm{v} / \mathrm{v})$ of Lactobacillus acidophilus (F-DVS LA-K, Chr. Hansen's Laboratory, Milwaukee, WI, USA) in peptone water $(0.1 \% \mathrm{wt} / \mathrm{v})$ at room temperature $\left(21^{\circ} \mathrm{C}\right)$. The OSU-4 pulsed electric field processor (The Ohio State University, Columbus, $\mathrm{OH}$ ) was used to generate the pulsed electric field conditions. The treatments were pulse periods of 10,000 $\mu \mathrm{s}, 20,000 \mu \mathrm{s}$, and $30,000 \mu \mathrm{s}$, electric field strengths of 5,10 , and 15 $\mathrm{kV} / \mathrm{cm}$, and electric pulse widths of 3,6 , and $9 \mu \mathrm{s}$. Control was run through the PEF equipment at $60 \mathrm{~mL} / \mathrm{min}$, without receiving any pulsed electric field treatment. Growth was evaluated hourly over 16 hours of incubation. The experimental design was a repeated measure design. Three replications were conducted.

\section{Growth}

Growth of Lactobacillus acidophilus LA-K was determined according to Loghavi et al. [7]. The growth was monitored by measuring the optical density at $600 \mathrm{~nm}$ (OD 600) through an UVVis Spectrophotometer (Nicolet Evolution 100, Thermo Scientific; Madison, WI, USA). Control and PEF treated samples were inoculated $(10 \% \mathrm{v} / \mathrm{v})$ into MRS broth (Criterion ${ }^{\mathrm{TM}}$, Hardy Diagnostics, Santa Maria, CA), which was previously autoclaved at $121^{\circ} \mathrm{C}$ for $15 \mathrm{~min}$ with pH $6.5 \pm 0.2$. The inoculated MRS broth had an initial OD 600 of 0.200 \pm 0.005 , and was incubated under anaerobic conditions at $37^{\circ} \mathrm{C}$ for 16 hours. The OD values were collected hourly. The spectrophotometer was calibrated by using MRS broth as blank. An average of two values per treatment was taken, i.e. two cuvettes per treatment. An estimate of bacterial counts $(\mathrm{CFU} / \mathrm{mL})$ was calculated from OD 600 readings, using a standard curve (Figure 1).

\section{Statistical analysis}

An analysis of the data was done using PROC GLM of the Statistical Analysis Systems. Differences of least square means were used to determine significant differences at $P<0.05$ for main effects and interaction effects. Data are presented as mean \pm standard error of means. Significant differences were determined at $\alpha=0.05$.

\section{Results and Discussion}

\section{Pulse period effect on growth}

The OD values at different pulse periods over the growth period of 16 hours are shown in figure 2. Various treatments applied are in table

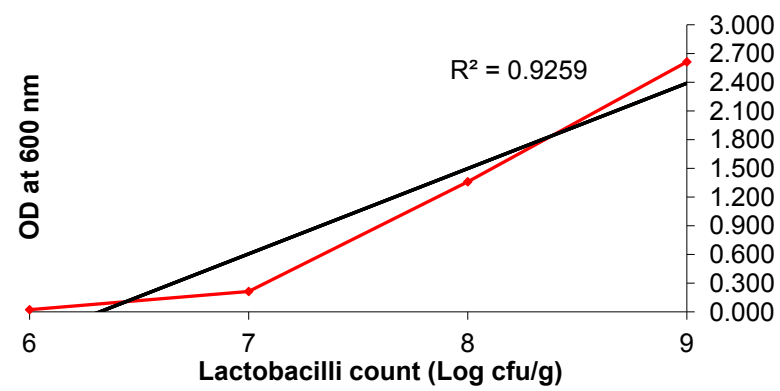

Figure 1: Standard curve for growth of LA-K in MRS broth.

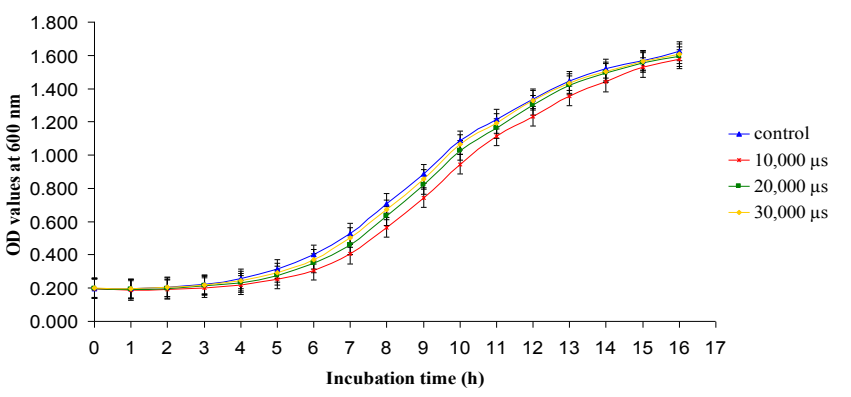

Figure 2: Pulse period effect on growth of LA-K.

\begin{tabular}{|l|l|}
\hline Treatment parameter & Condition \\
\hline Bipolar pulse width $(\mu \mathrm{s})$ & 3 \\
Electric field strength $(\mathrm{kV} / \mathrm{cm})$ & 25 \\
Pulse period $(\mu \mathrm{s})$ & 10,$000 ; 20,000 ; 30,000$ \\
Delay time $(\mu \mathrm{s})$ & 20 \\
Flow rate $(\mathrm{mL} / \mathrm{min})$ & 60 \\
\hline
\end{tabular}

Table 1: Pulsed Electric Field (PEF) treatment conditions applied during the study of the influence of various pulse periods on Lactobacillus acidophilus LA-K.

\begin{tabular}{|l|l|}
\hline & Growth \\
\hline Source & MS Pr $>$ F \\
\hline Pulse period & $0.070<0.0017$ \\
Hour & $4.840<0.0001$ \\
Pulse period*hour & $0.002<1.0000$ \\
Error & 0.013 \\
\hline Table 2: Mean Square (MS) and Pr $>$ F of pulse period, hour and their interaction for \\
\hline
\end{tabular}
growth characteristics, bile tolerance and protease activity.

1. Pulse period ${ }^{\star}$ hour interaction effect was not significant $(p=1.0000)$ (Table 2). Pulse period had a significant $(\mathrm{p}=0.0017)$ influence on the growth curve (Table 2). According to table 3 , there were no significant differences among the control, 30,000 $\mu$ s and 20,000 $\mu$ s. The growth curve subjected to the pulse period of $10,000 \mu$ s was significantly lower than the growth curve of control and the growth curve subjected at $30,000 \mu \mathrm{s}$.

\section{Electric field strength influence on growth}

The OD values at different electric field strengths over the growth period of 16 hours are shown in figure 3. Treatments applied are shown in table 4 . Voltage hour interaction effect was not significant $(\mathrm{p}=0.2706)$ (Table 5). Voltage had a significant $(\mathrm{p}<0.0001)$ influence on the growth curve (Table 5). The LA-K subjected to 15 and $25 \mathrm{kV} / \mathrm{cm}$ had significantly lower growth than the control and $5 \mathrm{kV} / \mathrm{cm}$ (Table 6). There were no significant differences between the control and $5 \mathrm{kV} / \mathrm{cm}$. Furthermore, there were no significant differences between the growth curves at 15 and $25 \mathrm{kV} / \mathrm{cm}$. 
Citation: Cueva O, Aryana KJ (2012) Influence of Certain Pulsed Electric Field Conditions on the Growth of Lactobacillus acidophilus LA-K. J Microb Biochem Technol 4: 137-140. doi:10.4172/1948-5948.1000084

\section{Pulse width influence on growth}

The OD at different bipolar pulse widths over the growth curve period of 16 hours are shown in figure 4. Various treatments applied are in table 7 . Bipolar pulse width*hour interaction effect was significant ( $\mathrm{p}=0.0155$ ) (Table 8). From hours 5 to 10 , there were significant differences between the control and the different bipolar pulse widths. Bipolar pulse width effect had a significant $(\mathrm{p}<0.0001)$ influence on the growth curve (Table 8 ). The growth curve of the

\begin{tabular}{|l|l|}
\hline & Growth \\
\hline Treatment & LS Mean \\
\hline Control & $0.808^{\mathrm{A}}$ \\
$10,000 \mu \mathrm{s}$ & $0.733^{\mathrm{B}}$ \\
$20,000 \mu \mathrm{s}$ & $0.772^{\mathrm{AB}}$ \\
$30,000 \mu \mathrm{s}$ & $0.792^{\mathrm{A}}$ \\
\hline
\end{tabular}

LS Mean with same letter are not significantly different $(p<0.05)$

Table 3: Least square means for growth characteristics, bile tolerance and acid tolerance, as influenced by pulse period.

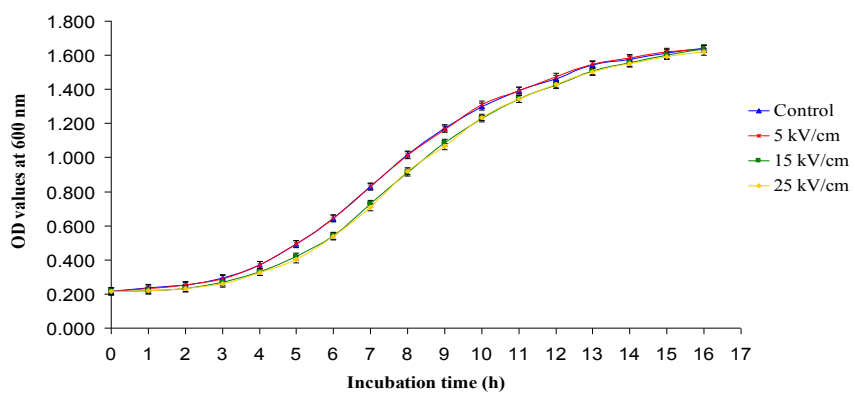

Figure 3: Electric Field Strength influence on LA-K.

\begin{tabular}{|l|l|}
\hline Treatment parameter & Condition \\
\hline Bipolar pulse width $(\mu \mathrm{s})$ & 3 \\
Electric field strength $(\mathrm{kV} / \mathrm{cm})$ & $5 ; 15 ; 25$ \\
Pulse period $(\mu \mathrm{s})$ & 30,000 \\
Delay time $(\mu \mathrm{s})$ & 20 \\
Flow rate $(\mathrm{mL} / \mathrm{min})$ & 60 \\
\hline
\end{tabular}

Table 4: Pulsed Electric Field (PEF) treatment conditions applied during the study of the influence of various electric field strengths on Lactobacillus acidophilus LAK.

\begin{tabular}{|l|l|}
\hline & Growth \\
\hline Source & MS Pr $>$ F \\
\hline Voltage & $0.044<0.0001$ \\
Hour & $3.698<0.0001$ \\
Voltage*hour & $0.001<0.2706$ \\
\hline Error & 0.001 \\
\hline
\end{tabular}

Table 5: Mean Square (MS) and Pr>F of voltage, hour and their interaction for growth characteristics, bile tolerance and protease activity.

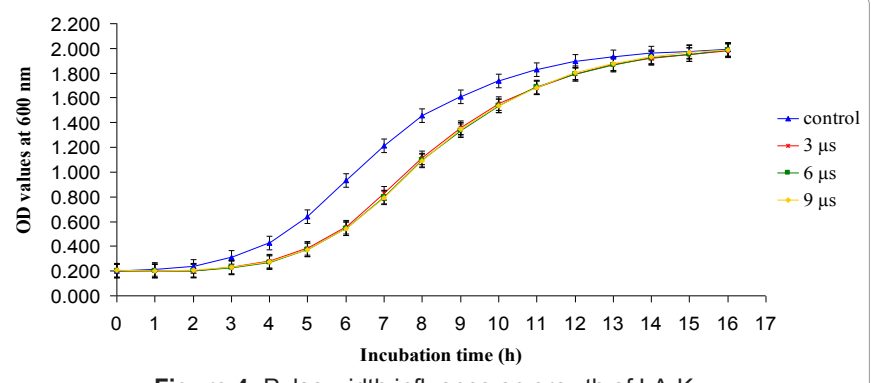

Figure 4: Pulse width influence on growth of LA-K.

\begin{tabular}{|l|l|}
\hline & Growth \\
\hline Treatment & LS Mean \\
\hline Control & $0.945^{\mathrm{A}}$ \\
$5 \mathrm{kV} / \mathrm{cm}$ & $0.946^{\mathrm{A}}$ \\
$15 \mathrm{kV} / \mathrm{cm}$ & $0.897^{\mathrm{B}}$ \\
$25 \mathrm{kV} / \mathrm{cm}$ & $0.892^{\mathrm{B}}$ \\
\hline
\end{tabular}

LS Mean with same letter are not significantly different $(p<0.05)$

Table 6: Least square means for growth characteristics, bile tolerance and acid tolerance, as influenced by voltage.

\begin{tabular}{|l|l|}
\hline Treatment parameter & Condition \\
\hline Bipolar pulse width $(\mu \mathrm{s})$ & $3,6,9$ \\
Electric field strength $(\mathrm{kV} / \mathrm{cm})$ & 25 \\
Pulse period $(\mu \mathrm{s})$ & 10,000 \\
Delay time $(\mu \mathrm{s})$ & 20 \\
Flow rate $(\mathrm{mL} / \mathrm{min})$ & 60 \\
\hline
\end{tabular}

Table 7: Pulsed Electric Field (PEF) treatment conditions applied during the study of the influence of various pulse widths on Lactobacillus acidophilus LA-K.

\begin{tabular}{|l|l|}
\hline & Growth \\
\hline Source & MS Pr>F \\
\hline Pulse width & $0.278<0.0001$ \\
Hour & $6.384<0.0001$ \\
Pulse width*hour & $0.015<0.0155$ \\
Error & 0.009 \\
\hline
\end{tabular}

Table 8: Mean Square (MS) and $\mathrm{Pr}>\mathrm{F}$ of pulse width, hour and their interaction for growth characteristics, bile tolerance and protease activity.

\begin{tabular}{|l|l|}
\hline & Growth \\
\hline Treatment & LS Mean \\
\hline Control & $1.210^{\mathrm{A}}$ \\
$3 \mu \mathrm{s}$ & $1.066^{\mathrm{B}}$ \\
$6 \mu \mathrm{s}$ & $1.059^{\mathrm{B}}$ \\
$9 \mu \mathrm{s}$ & $1.062^{\mathrm{B}}$ \\
\hline
\end{tabular}

LS Mean with same letter are not significantly different $(p<0.05)$

Table 9: Least square means for growth characteristics, bile tolerance and acid tolerance, as influenced by pulse width.

control was significantly higher than the growth curves subjected at any of the bipolar pulse widths studied. There were no significant differences among the three different bipolar pulse widths (Table 9). The logarithmic phase of Lactobacillus LA-K in control was reached faster, than when treated at different bipolar pulse widths. The slope in the growth curve of the control was higher than the slope of the curve of the different bipolar pulse widths. From hours 5 to 10, the control was an average of OD 0.300 higher than the different bipolar pulse widths.

According to Hülsheger et al. [8], bacterial cells in the stationary and lag growth are more resistant to PEF treatments than exponentially growing cells. The reason of this is because microbial growth in logarithmic phase is characterized by a high proportion of cells undergoing division, during which the cell membrane is more susceptible to the applied electric field.

\section{Conclusion}

Electric field strength significantly influenced growth of Lactobacillus acidophilus LA-K. Growth of the control LA-K and LA-K subjected to $5 \mathrm{kV} / \mathrm{cm}$ were higher than growth of LA-K subjected to 15 and $25 \mathrm{kV} / \mathrm{cm}$. Bipolar pulse width and pulse period slowed log stage growth of Lactobacillus acidophilus LA-K. Slower growth of adjunct bacteria can sometimes be good in the manufacture of cultured dairy foods, as it results in controlled release of bacterial enzymes for improved flavor and texture development. 
Citation: Cueva O, Aryana KJ (2012) Influence of Certain Pulsed Electric Field Conditions on the Growth of Lactobacillus acidophilus LA-K. J Microb Biochem Technol 4: 137-140. doi:10.4172/1948-5948.1000084

\section{References}

1. Pothakamury UR, Monsalvegonzalez A, Barbosacanovas GV, Swanson BG (1995) High-voltage pulsed electric-field inactivation of Bacillus-subtilis and Lactobacillus-delbrueckii. Food Sci Technol Int 35: 101-107.

2. Qin BL, Barbosa-Cánovas GV, Swanson BG, Pedrow PD, Olsen RG (1998) Inactivating microorganisms using a pulsed electric field continuous treatment system. IEEE Trans Ind Appl 34: 43-50.

3. Grahl T, Märkl H (1996) Killing of microorganisms by pulsed electric fields. Appl Microbiol Biotechnol 45: 148-157.

4. Rivas A, Sampedro F, Rodrigo D, Martínez A, Rodrigo M (2006) Nature of the inactivation of Escherichia coli suspended in an orange juice and milk beverage. Eur Food Res Technol 223: 541-545.

5. Fernandez-Molina JJ, Barkstrom E, Torstensson P, Barbosa-Cánovas GV Swanson BG (1999) Shelf-life extension of raw skim milk by combining heat and pulsed electric fields. Food Res Int.

6. Sobrino-López A, Raybaudi-Massilia R, Martín-Belloso O (2006) High-intensity pulsed electric field variables affecting Staphylococcus aureus inoculated in milk. J Dairy Sci 89: 3739-3748.

7. Loghavi L, Sastry SK, Yousef AE (2009) Biotechnology Progress 25: 85-94.

8. Hülsheger H, Potel J, Niemann EG (1983) Electric field effects on bacteria and yeast cells. Radiat Environ Biophys 22: 149-162. 